\title{
AC 2010-1038: EARLY CAREER BIOENGINEERING RESEARCH EXPERIENCE FOR UNDERGRADUATES
}

\section{Rebecca Willits, Saint Louis University}

Rebecca Kuntz Willits is an associate professor of Biomedical Engineering at Saint Louis University and has developed courses in Transport Phenomena, Biotransport, Drug Delivery, Tissue Engineering, and Design of Laboratory Experiments. She was the 2009 Director of BE@SLU, an NSF-sponsored REU in Bioengineering.

\section{David Barnett, Saint Louis University}

David Barnett is the Chairperson of the Department of Biomedical Engineering at Saint Louis University, as well as the Director of the 2010 BE@SLU program. 


\section{Early Career Bioengineering Research Experience for Undergraduates}

\section{Overview}

Research experiences for undergraduates are considered beneficial to recruit and retain interested and high performing students in engineering and science ${ }^{1}$. Yet, many programs designated as "Research Experience for Undergraduates" are directed at students entering their senior year, although it has been suggested that the experience begin earlier ${ }^{2}$. We designed and initiated a REU program that targets students in the early stages of their undergraduate career, specifically, those completing their first year in college. The goal of Bioengineering at Saint Louis University (BE@SLU) is to provide early undergraduate students (students entering their first or second years) with real examples of bioengineering career options (both research and industry) to sustain their interest in engineering through their early curricula. By exposing students to a bioengineering research experience after their freshman year, the students may be better able to recognize their academic interests and may have a better idea of their career options in engineering. The program is structured to accommodate these early career students, with peer mentoring, career discussions, and research training embedded into the program. The first week of the program, "Training Week" not only covers basic laboratory technique, but we also have a journal club (or how to find and read a research article), discussions on laboratory etiquette and research ethics. Participants were then integrated into their research mentors laboratory, and spent eight weeks on a research project. The program has two Peer Mentors, who are undergraduates with research experience, that live with the students and participate in the research project. The mentors are also responsible for additional social and academic activities during nights and weekends. This paper describes the program, evaluations and critiques from the first year (from both research mentors and participants), as well as the challenges and opportunities the program presents to future "Research Experience for Undergraduates" programs. Surveys will continue for those students who have already completed the program, to track their interest level and possible influence the program had on their interests.

\section{Introduction}

Saint Louis University (SLU) started a Research Experience for Undergraduates (REU) Program in Bioengineering with a consortium of faculty in the Departments of Chemistry, Biomedical Engineering, Aerospace \& Mechanical Engineering, Psychology, and Pharmacological and Physiological Sciences. Funded by the National Science Foundation (NSF), the goal of the program is to provide early undergraduate students (entering first- and second- year students) with real examples of bioengineering career options (both research and industry) to sustain their interest in engineering through their early curricula. Bioengineering at Saint Louis University (BE@SLU) began with Training Week, which spans topics in from cell and tissue culture to laboratory etiquette to reading journal articles. After Training Week, students work in the laboratories of their selected research mentors to complete an 8-week research project. As the students are early in their career (students entering their first or second years), the program also has a Peer Mentor system, where undergraduates experienced in research are integrated into the 
program to help the participants adjust to laboratories, to plan academic and social activities, to help train the participants, and to help the students prepare presentations and papers as needed. At the close of the program, students present their research as an oral presentation, which is evaluated by mentor scientists as well as other scientists, graduate students and guests.

\section{Program}

The 2009 REU program had eight participants, two of which were Peer Mentors. Although funded late in the cycle of applications, BE@SLU received over 50 applications for the 8 positions. We deemed this to be very successful as the target population of entering freshman and sophomores are not necessarily seeking research experiences through the REU programs. Two (of the 8) students were from primarily undergraduate institutions, $6 / 8$ were women, and 1/8 was a self-identified underrepresented minority (Native American). We are seeking to increase the number of underrepresented students through a number of mechanisms, including recruiting at Tribal Colleges through a faculty member at SLU who has close ties to the Society for the Advancement of Chicanos and Native Americans in Science (SACNAS) and advertising at websites specific for minorities in science and engineering (e.g., pathwaytoscience.org). The program is open to entering freshman and these students were recruited primarily through the accepted students at SLU and local high school programs. However, for the first year, only rising sophomores were accepted for a variety of reasons; we hope this pool will expand in the future. At the time of application, each student was asked to give mentor or research preferences based on the advertising and all participants were matched with their chosen mentors. Only a few Peer Mentor applications were received; this problem was anticipated for the first year as (1) we started late in the process and (2) we were hoping to recruit previous participants to apply as Peer Mentors and 2009 was the first year of the program. Therefore, the selected Peer Mentors were from the home institution, had significant research experience, and were well versed in the SLU community, which was very beneficial in the first year of the program. Participants were asked for written feedback throughout and after the program, and that feedback will be utilized to improve and focus the future programs.

\section{Development Activities}

An overview of the activities of BE@SLU are listed in Table 1. BE@SLU began with Training Week (Table 2), which was especially important for this REU program as it focused on early career students. Training Week gave the participants a chance to slowly integrate into their laboratories, while still performing group activities. General training, as noted in Table 1, gave the participants broader exposure to bioengineering and research and allowed them the opportunity to discuss their projects with the group as they were starting. Other activities outside of the research experience included two career panels (one graduate and one professional), two industrial tours (Covidien and Sigma), and a final presentation and paper. A writing assignment was required after each career panel, which was focused on either a cover letter or personal statement for the next step in their career. After Training Week and feedback from the participants, a "Mentor Seminar" series was added. Each Wednesday, a faculty mentor gave a 'tutorial' presentation on their research interests and it's application to bioengineering. 
Table 1: Program activites and the corresponding evaluation from the students during the program.

\begin{tabular}{|l|l|l|}
\hline Date & Activity & Evaluation (\% positive) \\
\hline June $1-5$ & Training Week & $100 \%$ \\
\hline June 11 & Goals Presentation (10 min) & $100 \%$ \\
\hline June 18 & Covidien Tour & $38 \%$ \\
\hline June 25 & Career Panel & $100 \%$ \\
\hline June 29 & Career "Cover Letter" due & $75 \%$ \\
\hline July 1 & Personal progress evaluation due & NA \\
\hline July 2 & Meet with coordinator to discuss progress & $100 \%$ \\
\hline July 9 & Sigma-Aldrich Tour & $100 \%$ \\
\hline July 16 & Graduate School Panel & $75 \%$ \\
\hline July 20 & Graduate "Personal Statement" due & $75 \%$ \\
\hline July 30 & Final Presentation & NA \\
\hline July 31 & Final Paper and Website due & NA \\
\hline
\end{tabular}

\begin{tabular}{|c|c|}
\hline Day & Activities \\
\hline 1 & $\begin{array}{ll}\text { - } & \text { Introductions } \\
\text { - } & \text { ID cards } \\
\text { - } & \text { Meeting with research advisor } \\
\text { - } & \text { Begin literature searches for project } \\
\text { - } & \text { Read } 2 \text { articles for journal club by Peer Mentors }\end{array}$ \\
\hline 2 & $\begin{array}{l}\text { - } \quad \text { Laboratory Training: Sterile Technique } \\
\text { - } \quad \text { Presentation (1 slide) of Project Description } \\
\text { - Journal Club (Peer Mentors) } \\
\text { - } \quad \text { Find article (related to project) for Journal Club }\end{array}$ \\
\hline 3 & $\begin{array}{l}\text { - Journal Club Presentations (3) } \\
\text { - } \quad \text { Laboratory Training: Cell Culture } \\
\text { - } \quad \text { Research Training: Laboratory Notebook } \\
\text { - } \quad \text { Research Training: Research Ethics } \\
\text { - } \quad \text { Research Training: Laboratory Etiquette }\end{array}$ \\
\hline 4 & $\begin{array}{ll}\text { - } & \text { Journal Club Presentations (3) } \\
\text { - } & \text { Laboratory Training: Cell Culture Continued } \\
\text { - } & \text { Notebook check } \\
\text { - } & \text { Visit research laboratory } \\
\text { - } & \text { Preparing Goals Presentation (week 2) }\end{array}$ \\
\hline 5 & $\begin{array}{l}\text { - Continue sterile technique/cell culture training as necessary } \\
\text { - Assisted literature review } \\
\text { - Research laboratory }\end{array}$ \\
\hline
\end{tabular}


While BE@SLU coordinated 2 career panels, the participants ended up going to three different panels. The first panel had 3 participants: Panelist 1 (BS BME, JD), Panelist 2 (BS BME, MD/PhD candidate), Panelist 3 (BS BME, MS Heathcare Technology). They briefly described their career path and how they determined what they wanted to do. The participants then asked questions of the panel. The second panel had 5 participants: Panelist 1 (BS BME, PhD BME, Startup Company), Panelist 2 (BS BME, PhD BME, Postdoc), Panelist 3 (BS BME, PhD BioEng candidate), Panelist 4 (BS BME, PhD BME candidate), Panelist 5 (BS BME, PhD BME, Teaching/Research Postdoc). The panelists described their path to graduate school (and beyond), as well as their research interests and how they decided on their schools. Questions from the participants were given to the panelists ahead of time so that their individual talks could be more focused for the participants. The extra panel was set up in the tour of Sigma-Aldrich, where three bioengineers on staff gave the participants insight into their careers and how they chose their path. Feedback from all of the panels was largely positive, although about 2 participants considered the second panel too homogeneous (refer to Lessons Learned below).

One component that likely contributed to the success of the panels was immediate follow up in small groups. Each panel was scheduled right before lunch so that after the panel was completed, small groups of the participants went to lunch with a panelist to get more one-on-one time and advice. This part of the panel was deemed the most successful by feedback from the participants. Although it was somewhat dependent upon the participants, most took advantage of this time to delve into the various opportunities available to them with a career in bioengineering. After some reflection on the panel, each participant was asked to write a statement (a 'cover letter' after the first panel and a 'personal statement' after the second panel) that was directed at a job or school of their choice. Each statement received feedback from at least 3 of the faculty mentors and was given back to the participants.

\section{Research Productivity}

After Training Week, the participants had 8 weeks to complete their research projects. It is important to note that while they had group activities during Training Week as noted in Table 2, the students met with their research advisors on the first day of the program to discuss their project. After this meeting, we were able to integrate discussions about their projects into Training Week. As the coordinator of the program, I felt that this week was a critical component for the students, however, the research advisors also gave positive feedback about the training after the program.

Overall, research projects were deemed successful, with 7 out of the 8 submitting abstracts for the Biomedical Engineering Society Annual Conference in Pittsburgh, PA in October 2009. Six students gave poster presentations, while 1 student gave an oral presentation. All students who attended gave extremely positive feedback regarding their attendance at the conference, noting that it was one of their favorite parts of the program. For example, one participant noted: "The conference and presentation have positively influenced my thoughts toward bioengineering. I really enjoyed discussing the results of my project with other attendees at the conference and learning about the work of others." 
As part of the program, all participants were required to do a final oral presentation, write a final paper, and make a project website. All websites are publically available and will be used as examples of previous projects (http://bioengreu.slu.edu/2009_Projects.html). As part of the website, many students posted their final presentations and papers, so those are also publically available. Having participants make their own website was a great way of improving and adding to our program's website. To provide the participants with peer feedback, peer evaluation forms were used during the final presentations; they were then typed and submitted back to each participant.

\section{Peer Mentors}

The Peer Mentors were an important component of the program, as it provided the participants experienced undergraduate researchers to seek out for advice. The participants were all rising sophomores and none had research experience, so the Peer Mentors not only acted as research and academic mentors, but also as social coordinators for the program. As the Peer Mentors were SLU students, they knew the surrounding area very well and helped coordinate everything from picking and dropping off participants at the airport to grocery shopping to research training assistance. They organized practice sessions for each presentation as well as weekly dinners to discuss research project and troubles. In addition, they organized weekly social events (such as July 4 Fireworks, visit to the Science Museum, or Minor League Baseball games) which were all well attended, and appreciated by the participants. The Peer Mentors also were active in the BE@SLU programming as participants. Feedback regarding the Peer Mentors was positive, although it is hard for the students to have a frame of reference for a program without the Peer Mentors.

\section{Lessons Learned}

As BE@SLU is a small program, our feedback was collected as open ended questions and not Likert-scaled questions during the program. Feedback after the program (our latest evaluation was sent out in December 2009) was a combination of scaled and open-ended feedback, to generate a response more quickly and easily (Table 1). Feedback to the program based on participant evaluations was overall very good, although it will likely initiate small changes to the BE@SLU program next year. The participants really enjoyed the Sigma-Aldrich tour (100\% recommended keeping the tour on the schedule), but the tour of Covidien was somewhat of a failure (5/8 recommended dropping the tour from the schedule). The tour was mostly outside, it was $>100^{\circ} \mathrm{F}$ and sunny that day, and was not directed toward engineers and scientists. While some of this is unavoidable, we will seek to work with the companies ahead of time regarding type of tour we would like, with the hope of making each of these activities as useful as possible. Although the individual tours may vary, all of the participants agreed that tours are a great way to examine their career options. For the writing assignments after the BE@SLU panels, 6/8 students felt that writing the statements and getting feedback from faculty was useful for their future career plans. One student was unsure and one student thought it was premature as they were only rising sophomores. With respect to the early "Goals Presentation", 8/8 felt that they should be continued as they learned a lot about their projects, although some suggested shorter times for the presentation. In addition, all students felt that the midsummer update was useful, as it, minimally, put their project in perspective. From the final evaluations, students suggested 
more contact with the research mentors ahead of the program. We will integrate this into the program by asking advisors to send out welcome emails after the assignment process, giving the participants a general feel for their project and maybe suggesting some references that might be useful. It is a careful balance that the we need to have, as the information needs to be the correct level as to not intimidate the participants. This item will be an important point for feedback and re-evaluation as the program progresses. Finally, feedback after the BMES conference was largely positive, further emphasizing the broad range of careers that can be pursued with a graduate degree in engineering.

Recent feedback (December 2009) was requested from the participants and we have received 6/8 responses. The questions were directed more at a reflection on the program and included scaled responses. Of the responses, 3/6 strongly agreed that the program gave them a positive impression of bioengineering research, with $3 / 6$ being neutral. Four respondents strongly agreed or agreed that participating in the program encouraged them to seek out research opportunities at their home institution, and it has been previously shown that research, especially substantive research experiences that come from multiple academic years, positively impacts the retention of students and their growth toward graduate school ${ }^{3}$. Five agreed or strongly agreed that the experience gave them confidence in their abilities for their chosen major, and all agreed or strongly agreed that BE@ SLU helped them decide on a career path, with 5/6 thinking that they will apply to graduate school.

In addition to the participant feedback, the research mentors were asked for feedback regarding the program and the participants. Five of the 6 advisors responded and all strongly agreed that REU programs are important to retain and train students in STEM disciplines. Only 1 of the 5 typically had first year students in the laboratory and all respondents stated that the students were similarly or better prepared for research in their laboratory than a typical undergraduate. In addition, all of the respondents felt that the participants accomplished similar amounts or more work than other undergraduates in their laboratory. One mentor wanted to see more interaction between themselves and the participants prior to the program (see note about this point above); all mentors had at least 1 conference presentation from the experience. One participant's summer work was included in a publication where the participant was the first author.

The peer mentors were asked several questions about the impact of being a mentor for the summer program. The mentors were asked if the program gave them leadership skills and organizational skills, if they learned about their ability to train others, if their research project was hampered by their additional activities, and if they would suggest someone become a peer mentor. Their feedback indicated that they gained skills and learned about their abilities, and mentoring did not hamper their research projects. One peer mentor noted: "A big part of what I got out of peer mentoring was my own abilities to teach people what I know. Teaching the students who had never had research experience before was a lot of fun and helped me improve on my skills in the lab!"

\section{Summary}

Although most REU programs are directed at rising juniors or seniors, the impact of such a research experience may be better felt by encouraging participation by rising sophomores. This 
program targeted those early career students, and after the first year of BE@SLU, we have not noted a difference in quality of research from a mentor prospective. Based on these early program evaluations, BE@SLU has also had an impact on the participants with respect to their chosen major and deciding on a career path that includes graduate school. We hope to continue to track the progress of our participants through their college education. The design of the programming activities was driven by the inexperience of the potential participants, and these activities, such as Peer Mentor activities and developmental activities, were positively received and did not hinder research productivity. Enhanced recruiting during the second year of the program will be targeted at improving the diversity of the participants. Finally, small modifications to the programming will be implemented based on the participants feedback.

\section{Bibliography}

1. Gregerman, SR, "The Role od Undergraduate Rsearch in Student Retention, Academic Engagement, and the Pursuit of Graduate Education", commisioned paper from Evidence on Promising Practices in Undergraduate Science, Technology, Engineering, and Mathematics (STEM) Education, National Academy, http://www7.nationalacademies.org/bose/Promising\%20Practices_Homepage.html.

2. Russell, SH, MP Hancock, and J McCullough, "Benefits of Undergraduate Research Experiences" Science 316(2007): 548-9.

3. Prince, MJ, RM Felder, and R Brent. "Does Faculty Research Improve Undergraduate Teaching? An Analysis of Existing and Potential Synergies" Journal of Engineering Education, 96(2007): 283-294. 